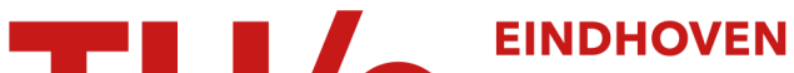 \\ UNIVERSITY OF \\ TECHNOLOGY
}

\section{Coordination for prosumers' electricity trading agents via distributed optimization}

\section{Citation for published version (APA):}

Dukovska, I., Paterakis, N. G., \& Slootweg, H. J. G. (2019). Coordination for prosumers' electricity trading agents via distributed optimization. In SEST 2019 - 2nd International Conference on Smart Energy Systems and Technologies [8849065] Institute of Electrical and Electronics Engineers. https://doi.org/10.1109/SEST.2019.8849065

\section{Document license:}

CC BY

DOI:

10.1109/SEST.2019.8849065

Document status and date:

Published: 01/09/2019

\section{Document Version:}

Accepted manuscript including changes made at the peer-review stage

\section{Please check the document version of this publication:}

- A submitted manuscript is the version of the article upon submission and before peer-review. There can be important differences between the submitted version and the official published version of record. People interested in the research are advised to contact the author for the final version of the publication, or visit the $\mathrm{DOI}$ to the publisher's website.

- The final author version and the galley proof are versions of the publication after peer review.

- The final published version features the final layout of the paper including the volume, issue and page numbers.

Link to publication

\section{General rights}

Copyright and moral rights for the publications made accessible in the public portal are retained by the authors and/or other copyright owners and it is a condition of accessing publications that users recognise and abide by the legal requirements associated with these rights.

- Users may download and print one copy of any publication from the public portal for the purpose of private study or research.

- You may not further distribute the material or use it for any profit-making activity or commercial gain

- You may freely distribute the URL identifying the publication in the public portal.

If the publication is distributed under the terms of Article $25 \mathrm{fa}$ of the Dutch Copyright Act, indicated by the "Taverne" license above, please follow below link for the End User Agreement:

www.tue.nl/taverne

Take down policy

If you believe that this document breaches copyright please contact us at:

openaccess@tue.nl

providing details and we will investigate your claim. 


\section{Coordination for Prosumers' Electricity Trading Agents via Distributed Optimization}

\author{
Irena Dukovska \\ Electrical Energy Systems \\ Department of Electrical Engineering \\ Eindhoven University of Technology \\ Eindhoven, the Netherlands \\ i.dukovska@tue.nl
}

\author{
Nikolaos G. Paterakis \\ Electrical Energy Systems \\ Department of Electrical Engineering \\ Eindhoven University of Technology \\ Eindhoven, the Netherlands \\ n.paterakis@tue.nl
}

\author{
Han (J.G.) Slootweg \\ Electrical Energy Systems \\ Department of Electrical Engineering \\ Eindhoven University of Technology \\ Eindhoven, the Netherlands \\ j.g.slootweg@tue.nl
}

\begin{abstract}
In this paper, the coordinated operation of agents representing residential household energy management systems in the electricity market is considered. Each agent has its local decision vector that may contain both continuous and discrete variables. The problem of minimizing the energy procurement cost of the community of agents is represented by a Mixed Integer Linear Program with local and global constraints. A dual decomposition method with a tightening of the global constraint is applied to solve the problem with guarantees for the feasibility of the obtained solutions. The problem is decomposed and solved in a distributed way with coordination by a community coordinator. The method is applied to a realistic case study of $\mathbf{1 5}$ households.
\end{abstract}

Index Terms-Decomposition methods, Distributed algorithms, Local Energy Trading, Optimization, Prosumers

\section{INTRODUCTION}

Technological advances such as the rollout of smart meters and the adoption of home energy management systems (HEMS) allow residential end-users to actively manage their own energy consumption and production [1]. The users actively embracing the aforementioned developments are referred to as prosumers [2]. In combination with developments in electricity markets, being able to actively manage residential electrical energy usage enables the emergence of novel market structures such as local community and peer-to-peer markets in which participating users can directly trade electricity between themselves.

The facilitation of such market structures requires to a large extent the integration of the cyber-system of the electricity market with the physical power network. The latter is inherently geographically distributed and embeds a variety of distributed energy resources and of participants groups that fulfill diverse and changing roles [2]. Hence, the question about how to effectively and efficiently coordinate a large number of heterogeneous agents with individual objectives and constraints in such a system naturally arises.

A common approach to solving these energy system operation challenges is the adoption of a centralized frame-

This work is part of the research programme "Enabling peer-to-peer energy trading by leveraging prosumer analytics" with project number 647.003 .003 , which is (partly) financed by the Netherlands Organisation for Scientific Research (NWO). work. However, foreseeing a large number of participants, a centralized approach is likely to present scalability and computational tractability issues. In this regard distributed algorithms for optimization and coordination represent an alternative method. These algorithms allow the bulk of computations to be performed locally by agents that obtain certain problem parameters via communication with a limited set of neighbors and/or a central coordinator [3]. There are several advantages of distributed over centralized approaches such as: 1) the reduction in the communication efforts and thus, the enhancement of cybersecurity and reduction of expenses for establishing communication networks; 2) the improvement of the robustness of the system with respect to the failure of individual agents; 3 ) the exploitation of the local intelligence of the distributed devices to improve computational performance overall; 4) the preservation of the privacy of data, measurements, cost functions and constraints [4].

Due to these advantages, there is a set of mathematical decomposition techniques that are applied to a number of optimization problems in the field of power systems [3], [4]. The most prominent technique is the Alternating Method of Multipliers (ADMM), that combines the augmented Lagrangian Relaxation and the Method of Multipliers with the Dual Decomposition method [4]. However, this method can guarantee convergence only in case the problem is convex. Nevertheless, it has been applied to non-convex, non-differentiable problems that also include integer variables. However, convergence to a global solution and even the feasibility of the obtained solutions cannot be guaranteed in such cases [3], [4]. Recently, methods to solve Mixed Integer Linear Problems (MILP) in a distributed manner, while ensuring the feasibility of the obtained solutions have been developed [5], [6].

This paper is inspired by these advancements in distributed optimization and control algorithms for solving problems in power systems. The goal is to extend these algorithms and apply them for solving the coordination problem of trading agents representing residential prosumers in a local electricity market, taking into account communication requirements and privacy concerns. A community of households with several controllable assets is modeled, with a focus on residential photovoltaic (PV) systems and electric vehicles (EV). Each house- 
hold is represented by an agent with its own objectives to be fulfilled by trading in the market. The system of trading agents is represented as a mixed-integer linear programming (MILP) problem, in which some of the constraints are shared among the agents [5], [6]. To facilitate the market coordination of the system, a distributed algorithmic framework is used, with limited communication with a central community coordinator.

The main contribution of this paper is twofold:

- The coordination of market trading agents representing residential prosumers by using distributed computation.

- The application of distributed algorithms for solving a MILP problem that represents the problem of local electricity trading between agents in power systems providing mathematical guarantees for the feasibility of the obtained solutions.

The remainder of the paper is organized as follows: the methodology, mathematical background, as well as the problem formulation are outlined in Section III The description of the case study, together with the presentation and discussion of results are given in Section III. Finally, conclusions and the future outlook of this study are presented in Section IV.

\section{Methodology}

\section{A. Problem formulation}

In this paper, the problem of coordinating a community of agents representing HEMS is analyzed. The agents can exchange electricity between themselves as well as with the rest of the grid. This is done at the connection point of the community of agents with the local distribution transformer, similarly to the centralized approach presented in [7]. This is also the point where the electricity is being dynamically priced. The objective of the community is to minimize the electricity costs of the participating agents.

Each participating HEMS has local constraints for its own production and consumption of electricity. Since the agents use the infrastructure of the electricity grid as a common resource, they also share some global constraints. Problems of this type can be cast as MILP problems, where some of the decision variables can take on discrete values, while the objective function is a sum of local linear cost functions. Each agent is responsible for minimizing its own cost function, while at the same time accounting for the coupling constraints. To facilitate this, a community coordinator is responsible for communicating with all HEMS agents information about the global constraints and therefore coordinating their operation. The constraints related to the operation of each household are considered locally and are not shared with other agents. Some information is exchanged between the community coordinator and the participating agents in the form of dual variables. A schematic diagram of the layout of the system and the shared information is presented in Fig. 1.

The main notation that is used in this paper is defined in Table I. Other symbols and abbreviations are defined where they first appear.

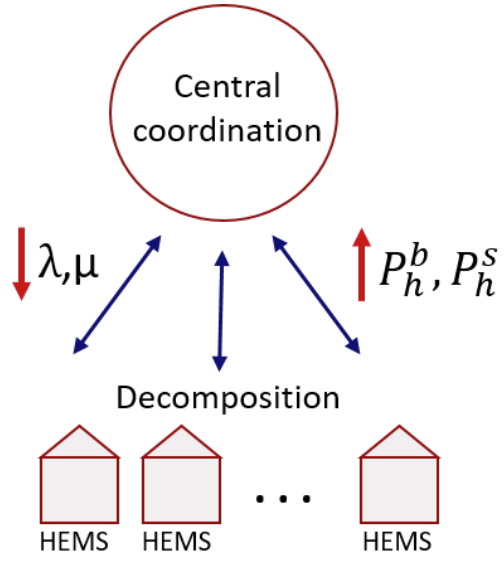

Fig. 1. Schematic diagram of coordination of the community of households.

\section{B. Mathematical background}

A MILP that represents an optimization problem as described above can be formalized as $P$.

$$
\begin{array}{r}
\min _{x} \sum_{i=1}^{n} c_{i}^{T} x_{i} \\
\\
\\
x_{i} \in X_{i}, i=1, \ldots, n
\end{array}
$$$$
\text { subject to: }
$$

where $x_{i} \in \mathbb{R}^{n}$ is the decision variable vector and $c_{i} \in \mathbb{R}^{n}$ is the corresponding cost vector of each agent. The coupling constraints are expressed through the matrices $A_{i} \in \mathbb{R}^{m} \times \mathbb{R}^{n}$ and the resource vector $b \in \mathbb{R}^{m}$. The sets $X_{i}=\left\{x_{i} \in \mathbb{R}^{r_{i}} \times \mathbb{Z}^{z_{i}}: D_{i} x_{i} \leq d_{i}\right\}$ define the local constraint sets.

The presence of discrete decision variables makes these problems hard to solve from a computational perspective, especially for a large number of agents. Therefore, they often require to be decomposed into a number of smaller-scale MILP problems. Moreover, a common practice for these problems is to construct the dual of the primal problem $P$, by dualizing the coupling constraint. The reasoning behind this is that the dual of the problem, $D$, can be easily decomposed despite the existence of the complicating coupling constraints [5]. As a result, the resulting problem can be solved in a distributed way. However, in that case, although the local constraints will be satisfied, there are no guarantees for the satisfaction of the coupling constraints [6].

$$
\max _{\lambda \geq 0}-\lambda^{T}(b)+\sum_{i=1}^{n} \min _{x_{i} \in X_{i}}\left(c_{i}^{T}+\lambda^{T} A_{i}\right) x_{i}
$$

To ensure the satisfaction of the coupling constraints, the dual problem can be solved through an iterative method, i.e., the subgradient algorithm. At each iteration, a candidate solution for the primal problem can be obtained. However, 
this does not necessarily satisfy the local constraints for the candidate solution, so feasibility for the obtained solution cannot be guaranteed [6]. In [5] a method to recover feasible primal solutions by using the dual optimal solution of a modified primal problem is used. This is achieved by tightening the coupling constraint by an appropriate amount $\rho$. The tightening is not applied directly to the original problem $P$. Instead, it is applied to the convexified, and hence linear, primal problem $P_{L P}$, resulting in the tightened linear problem $P_{L P, \rho}$. This is possible because the dual problem of $P_{L P}$ coincides with the dual of $P$ and because of the connection between the optimal solutions $x_{L P}^{*}\left(x_{L P, \rho}^{*}\right)$ to the linear problem $P_{L P}\left(P_{L P, \rho}\right)$ and the recovered primal solutions $x\left(\lambda^{*}\right)$ from the dual problem $D\left(D_{\rho}\right)$, respectively. The relevant proof can be found in [5].

$$
\begin{array}{rr}
\min _{x} & \sum_{i=1}^{n} c_{i}^{T} x_{i} \\
& \sum_{i=1}^{n} A_{i} x_{i} \leq b-\rho \\
& x_{i} \in \operatorname{conv}\left(X_{i}\right), i=1, \ldots, n
\end{array}
$$

where $\operatorname{conv}($.$) defines the convex hull.$

The dual of $P_{L P, \rho}$ is $D_{\rho}$.

$$
\max _{\lambda \leq 0}-\lambda^{T}(b-\rho)+\sum_{i=1}^{n} \min _{x_{i} \in X_{i}}\left(c_{i}^{T}+\lambda^{T} A_{i}\right) x_{i}
$$

where the $k$ th element of the contraction vector $\rho \in \mathbb{R}^{m}$ is $\rho_{k}$.

$$
[\rho]_{k}=m \max _{i \in 1, \ldots, m}\left(\max _{x_{i} \in X_{i}} A_{i}^{k} x_{i}-\min _{x_{i} \in X_{i}} A_{i}^{k} x_{i}\right) \quad\left(\rho_{k}\right)
$$

\section{Formulation of the optimization problem}

In this section, the mathematical formulation of the electricity trading agent coordination problem is detailed.

1) Objective function: The objective of the optimization problem is to minimize the total electricity procurement cost that the community of agents is exchanging with the grid and is expressed by (1).

$$
\min \sum_{h \in H} \sum_{t \in T}\left(P_{h, t}^{b} \cdot c_{t}^{b}-P_{h, t}^{s} \cdot c_{t}^{s}\right) \Delta T
$$

2) Coupling constraints: For a community of HEMS agents that are located in geographical proximity, it is assumed that they are connected to the same distribution transformer. Hence, the rated power of the transformer is considered as the limit of the energy that can be exchanged between the agents and the rest of the distribution network. This is enforced by (2) that explicitly accounts for bi-directional flow of energy.

\begin{tabular}{|c|c|}
\hline \multicolumn{2}{|l|}{ Sets and indices } \\
\hline$h(H)$ & Index (set) of households \\
\hline$t(T)$ & Index (set) of time intervals \\
\hline \multicolumn{2}{|l|}{ Parameters } \\
\hline$c_{t}^{b}$ & Buying price of electricity in period $t[€ / \mathrm{kWh}]$ \\
\hline$c_{t}^{s}$ & Selling price of electricity in period $t[€ / \mathrm{kWh}]$ \\
\hline$D_{h, t}^{i n f l}$ & Inflexible demand for household $h$ in period $t[\mathrm{~kW}]$. \\
\hline$P_{h}^{E V, R}$ & Charging rate of EV for household $h[\mathrm{~kW}]$ \\
\hline$P_{h}^{t_{\text {tim }}}$ & Power limit of the household $h[\mathrm{~kW}]$. \\
\hline$P_{h, t}^{P V}$ & $\begin{array}{l}\text { PV generated power for household } h \text { in period } \\
t[\mathrm{~kW}] .\end{array}$ \\
\hline$P_{T R, \max }$ & Export power limit of the transformer $[\mathrm{kW}]$. \\
\hline$P_{T R, \min }$ & Import power limit of the transformer $[\mathrm{kW}]$. \\
\hline$S O E_{h}^{E V, E O D}$ & SOE of EV at the end-of-day for household $h[\mathrm{kWh}]$ \\
\hline$S O E_{h}^{E V, i n i}$ & Initial SOE of EV for household $h[\mathrm{kWh}]$. \\
\hline$S O E_{h}^{E V, \max }$ & Maximum SOE of EV for household $h[\mathrm{kWh}]$. \\
\hline$S O E_{h}^{E V, \min }$ & Minimum SOE of EV for household $h[\mathrm{kWh}]$. \\
\hline & Arrival time of EV for household $h$. \\
\hline$T_{h}^{d}$ & Departure time of EV for household $h$. \\
\hline$\delta T^{h}$ & Time interval duration $[\mathrm{h}]$. \\
\hline \multicolumn{2}{|c|}{ Decision variables } \\
\hline$P_{h, t}^{b}$ & Power bought by household $h$ in period $t[\mathrm{~kW}]$. \\
\hline & Power sold by household $h$ in period $t[\mathrm{~kW}]$. \\
\hline$P_{h, t}^{E V, c h}$ & $\begin{array}{l}\text { Charging power of EV for household } h \text { in period } \\
t[\mathrm{~kW}] \text {. }\end{array}$ \\
\hline$P_{h, t}^{E V, d i s}$ & $\begin{array}{l}\text { Discharging power of EV for household } h \text { in period } \\
t[\mathrm{~kW}] \text {. }\end{array}$ \\
\hline$P_{h, t}^{E V, s}$ & $\begin{array}{l}\text { Portion of the EV discharging power exported for } \\
\text { selling by household } h \text { in period } t[\mathrm{~kW}]\end{array}$ \\
\hline$P_{h, t}^{E V, u}$ & $\begin{array}{l}\text { Portion of the EV discharging power self consumed } \\
\text { by household } h \text { in period } t[\mathrm{~kW}] \text {. }\end{array}$ \\
\hline$P_{h, t}^{P V, s}$ & $\begin{array}{l}\text { Portion of the PV power exported for selling } \\
\text { by household } h \text { in period } t[\mathrm{~kW}]\end{array}$ \\
\hline$P_{h, t}^{P V, u}$ & $\begin{array}{l}\text { Portion of the PV power self consumed } \\
\text { by household } h \text { in period } t[\mathrm{~kW}]\end{array}$ \\
\hline$S O E_{h, t}^{E V}$ & SOE of EV for household $h$ in period $t[\mathrm{kWh}]$ \\
\hline$u_{E V, t}$ & $\begin{array}{l}\text { Binary variable; } 1 \text { if the } \mathrm{EV} \text { is charging in period } t \text {, } \\
\text { else } 0 .\end{array}$ \\
\hline$u_{h, t}$ & $\begin{array}{l}\text { Binary variable; } 1 \text { if the household is importing } \\
\text { power in period } t \text {, else } 0 .\end{array}$ \\
\hline
\end{tabular}

$$
P^{T R, \min } \leq \sum_{h \in H}\left(P_{h, t}^{b}-P_{h, t}^{s}\right) \leq P^{T R, \max }, \forall t \in T
$$

TABLE I

NOMENCLATURE

3) Local constraints: Each HEMS agent has a set of local constraints that define the operation of the assets in the household, such as the PV system and the EV, as well as the inflexible demand.

The constraints related to the power exchange at a household level are expressed by (3)-(6). More specifically, the individual household power balance is given by (3). The power that can be sold is determined by (4). Also, at each time interval, each household can either buy or sell electricity, which is decided by the binary variable $u_{h, t}$ in the expressions for the household limit of power that can be sold or bought in (5) and (6).

$$
\begin{array}{rlrl}
P_{h, t}^{b}+P_{h, t}^{E V, u}+P_{h, t}^{P V, u} & =D_{h, t}^{i n f l}+P_{h, t}^{E V, c h}, & & \forall h, t \\
P_{h, t}^{s} & =P_{h, t}^{E V, s}+P_{h, t}^{P V, s}, & & \forall h, t \\
P_{h, t}^{s} \leq u_{h, t} \cdot P_{h}^{l i m}, & & \forall h, t \\
P_{h, t}^{b} \leq\left(1-u_{h, t}\right) \cdot P_{h}^{l i m}, & & \forall h, t
\end{array}
$$


The constraints that define the operation of the EV are described by equations (7)-(13). In (7), it is defined whether power discharged by the EV will be used in the household or sold. In particular, charging and discharging limits for the EV are enforced by (8) and (9). The boundaries for the state-of-energy (SOE) of the EV are defined by (10), whereas the required charge level at the end of the simulation period is enforced by (11). Constraints (12) and (13) update the SOE of the EV.

$$
\begin{gathered}
P_{h, t}^{E V, u}+P_{h, t}^{E V, s}=P_{h, t}^{E V, d i s} \cdot \eta_{d i s}^{E V} \\
0 \leq P_{h, t}^{E V, c h} \leq u_{E V, t} \cdot P_{h}^{E V, R}, \forall h, t \in\left[T_{h}^{a}, T_{h}^{d}\right] \\
0 \leq P_{h, t}^{E V, d i s} \leq\left(1-u_{E V, t}\right) \cdot P_{h}^{E V, R}, \forall h, t \in\left[T_{h}^{a}, T_{h}^{d}\right] \\
S O E_{h}^{E V, m i n} \leq S O E_{h, t} \leq S O E_{h}^{E V, m a x}, \forall h, t \\
S O E_{h, t}=S O E_{h}^{E V, e o d} \forall h, i f t=T_{h}^{d} \\
S O E_{h, t}=S O E_{h}^{E V, i n i}+\left(\eta_{c h}^{E V} \cdot P_{h, t}^{E V, c h}-P_{h, t}^{E V, d i s}\right) \\
\cdot \Delta T, \forall h, t=T_{h}^{a} \\
S O E_{h, t}=S O E_{h, t-1}^{E V}+\left(\eta_{c h}^{E V} \cdot P_{h, t}^{E V, c h}-P_{h, t}^{E V, d i s}\right) \\
\cdot \Delta T, \forall h, t \in\left(T_{h}^{a}, T_{h}^{d}\right]
\end{gathered}
$$

Finally, the power generated by the PV is either used or sold to the community as described by (14).

$$
P_{h, t}^{P V}=P_{h, t}^{P V, s}+P_{h, t}^{P V, u}, \forall h, t
$$

\section{Solution method}

The problem of coordinating the household agents is solved using the methodology presented in Section II-B. The contraction $\rho$ is calculated by 15 .

$$
\begin{array}{r}
{[\rho]_{t}=T \max _{h \in H}\left[\max _{x_{i} \in X_{i}} \sum_{h}\left(P_{h, t}^{b}-P_{h, t}^{s}\right)-\min _{x_{i} \in X_{i}}\right.} \\
\left.\sum_{h}\left(P_{h, t}^{b}-P_{h, t}^{s}\right)\right]=2 \cdot T \max _{h} P_{h}^{l i m}
\end{array}
$$

where $[.]_{t}$ defines the $t$-th element of the contraction vector $\rho$.

The dual function of the problem that is defined by equations (1)-14 is represented by (16.

$$
\begin{aligned}
\sup _{\boldsymbol{\lambda}, \boldsymbol{\mu} \geq \mathbf{0}} & \sum_{h} \min _{t \in T} \sum_{t}\left[P_{h, t}^{b} \cdot\left(c_{t}^{b}+\sigma^{b}-\lambda_{t}+\mu_{t}\right)-P_{h, t}^{s} \cdot\left(c_{t}^{s}\right.\right. \\
& \left.\left.+\sigma^{s}-\lambda_{t}+\mu_{t}\right)\right]+\left(\lambda_{t} \bar{P}^{T R, \min }-\mu_{T} \bar{P}^{T R, \max }\right)
\end{aligned}
$$

where $\bar{P}^{T R, \text { min }}=P^{T R, \text { min }}+\rho, \forall t \in T$ and $\bar{P}^{T R, \max }=P^{T R, \max }-\rho, \forall t$. The dual variables $\boldsymbol{\lambda}$ and $\boldsymbol{\mu}$ are related to the lower and upper transformer power boundary respectively. They are fixed at each iteration step and communicated to all the HEMS agents. Small perturbation terms $\sigma^{b}$ and $\sigma^{s}$ are added to ensure uniqueness of the solution of the $P_{P L, \rho}$ and $D_{\rho}$ [5].

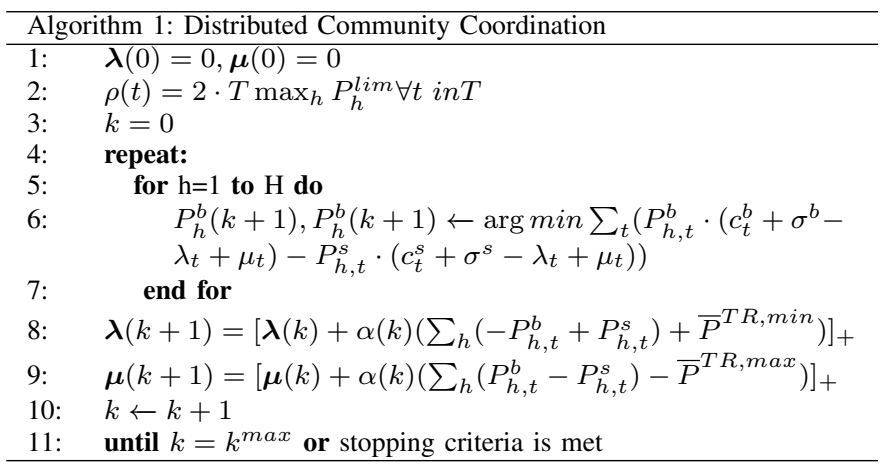

The inner minimization problem is decomposed and solved for each agent individually as a general optimization problem for the primal variables. The outer maximization problem is solved with a subgradient method with a constant step size. Moreover, projection onto the non-negative orthant is done for the dual variables.

The solution method is presented in Algorithm 1. Solving the inner optimization problems for each agent individually is done in steps 5-7. The dual variables are updated in steps 8 and 9 , where the projection on the positive orthant is represented by $[\cdot]_{+}$.

\section{CASE STUDY AND RESUlTS}

\section{A. Description of case study}

The methodology that was presented in the previous section was implemented in Python 3.6 and the optimization problems were solved using the Gurobi solver [8].

In the case study, measurements of the energy consumption and production of prosumers with a 15-min timestamp from the Pecan Street Research Institutes Dataport were used as inputs for the household agents models [9]. A community of 15 households is analyzed. Without loss of generality, each household is assumed to have an EV and a PV system, while the rest of the demand is considered to be inflexible. It is to be noted that the proposed methodology can be readily expanded to cover other controllable load types by extending the local constraint set. The energy required to charge each $\mathrm{EV}$ is equal to the measured daily energy from the dataset, whereas the initial charge is assumed to be $30 \%$ of the battery capacity. The arrival time of each EV, the battery capacity and the charging/discharging rate are also taken from the dataset. The households IDs used are listed in Table I An example of the used disaggregated time series for one household is illustrated in Fig. 2, where Power-Time-Unit (PTU) refers to 15-min time intervals.

The transformer is sized in accordance with the number of households. For the electricity prices, day-ahead market prices from the Dutch market were used [10]. The simulation

TABLE II

Pecan Street Household IDs Used In This Study 


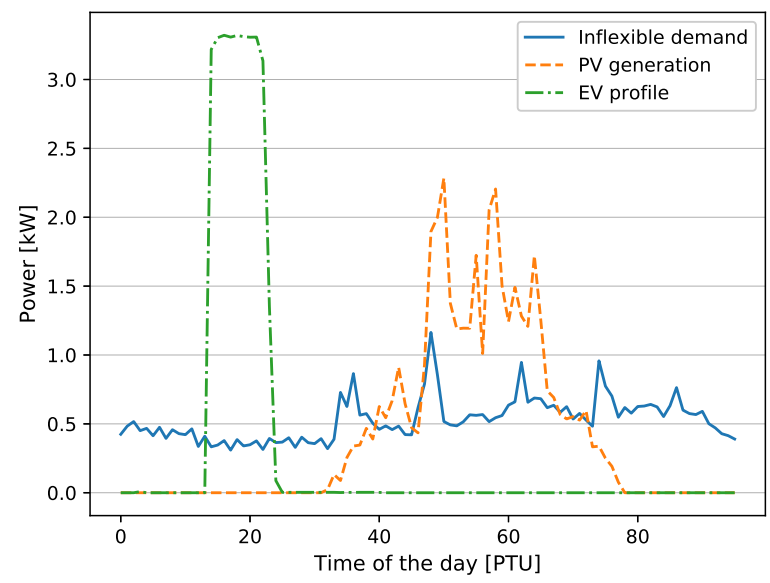

Fig. 2. Pecan Street data for one household.

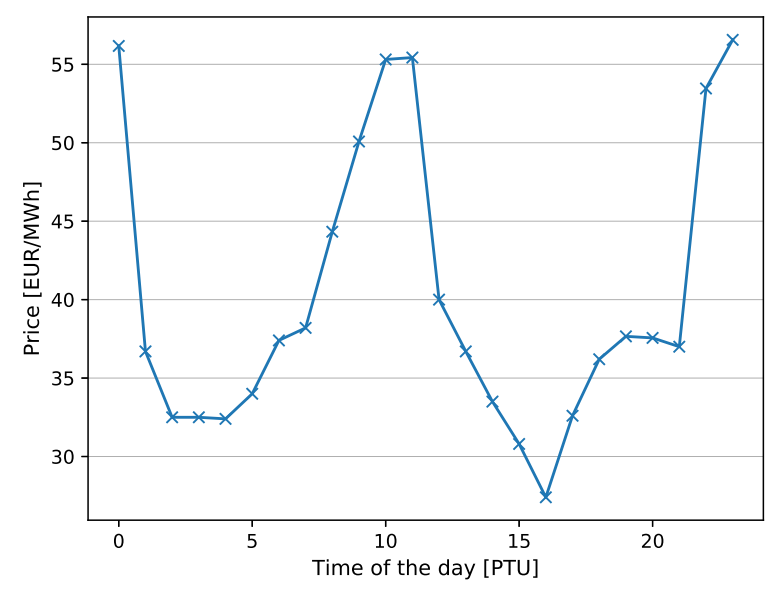

Fig. 3. Day ahead market prices for April 2, 2018.

is performed for the first Monday in April 2018 and the prices for that day are depicted in Fig. 3. It is considered that a feed-in-tariff scheme exists at the community level and that $c_{t}^{s}=1.1 \cdot c_{t}^{b}$. The optimization is performed for one day, with a time resolution of 15-minute intervals. For the subgradient method for solving the outer problem, the constant step size used for the updates of the dual variables is reduced every 25 iterations, as in [5].

\section{B. Simulation results}

In this section, the results from the performed simulations are presented and discussed. First, the convergence of the dual objective function and the dual variables is demonstrated by Figs. 4 and 5 To evaluate the convergence of the dual objective function, the primal problem is solved with a centralized approach and is used as a benchmark in Fig. 4 Although the dual objective converges, a gap between the optimal value and the dual function remains. The reason for this is the relatively small number of agents. The problems of type $P$, like the one

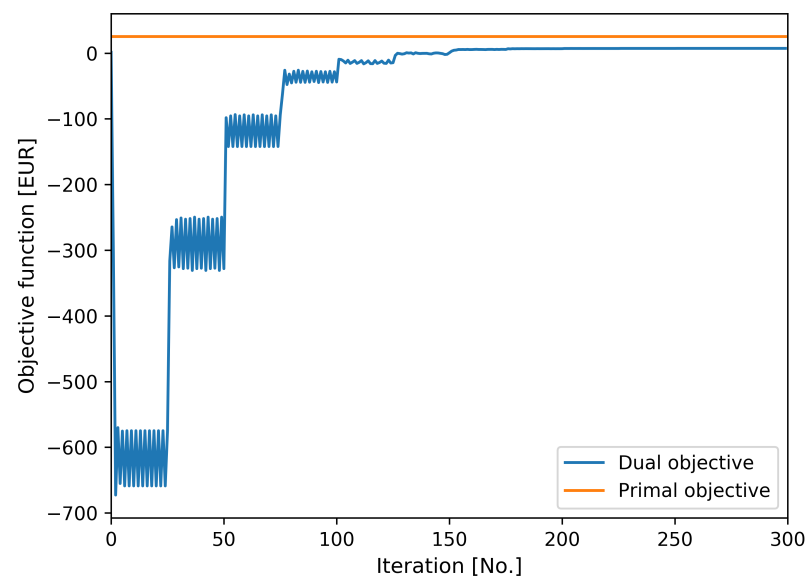

Fig. 4. Dual objective at each iteration.

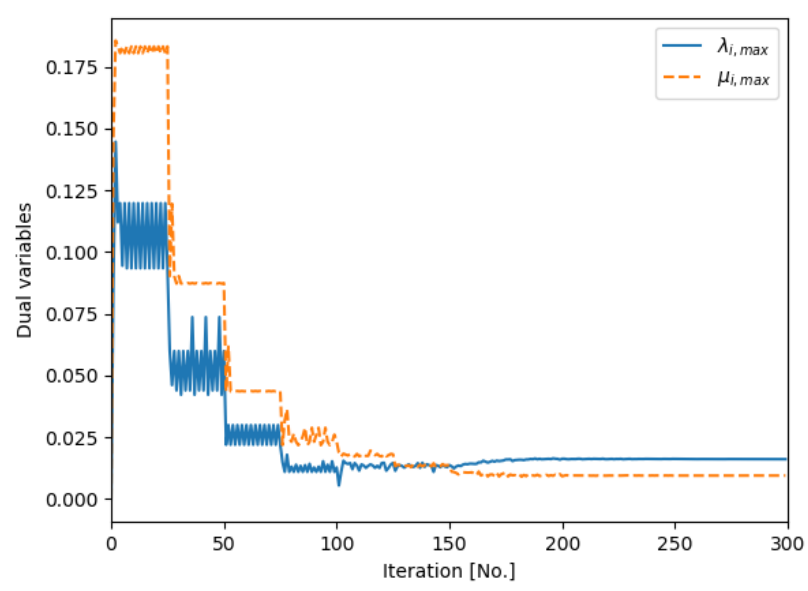

Fig. 5. Dual variables at each iteration.

that is solved in this paper, tend to get closer to a convex problem as the number of agents increases, in which case the duality gap between the primal $P$ and the dual problem $D$ decreases significantly and even vanishes [5].

The convergence behavior of the dual variables can be seen in Fig. 5 where the maximum values of the vectors per iteration are given. They start to converge approximately at the same iteration step similar to the dual function. The dual variable $\lambda$, that corresponds to the upper boundary is larger than the one for the lower boundary $\mu$, indicating that the upper boundary is more often and to a larger extent violated. This behavior can also be noticed in Fig. 6, where the maximum violation of the boundaries per iteration is recorded. Note that violations do not necessarily occur at every time step. On the contrary, they occur in a few time steps per iteration. Moreover, although there are minor violations to both bounds for the contracted problem, all solutions that are obtained are feasible for the original problem.

The power that is imported and exported from all the 


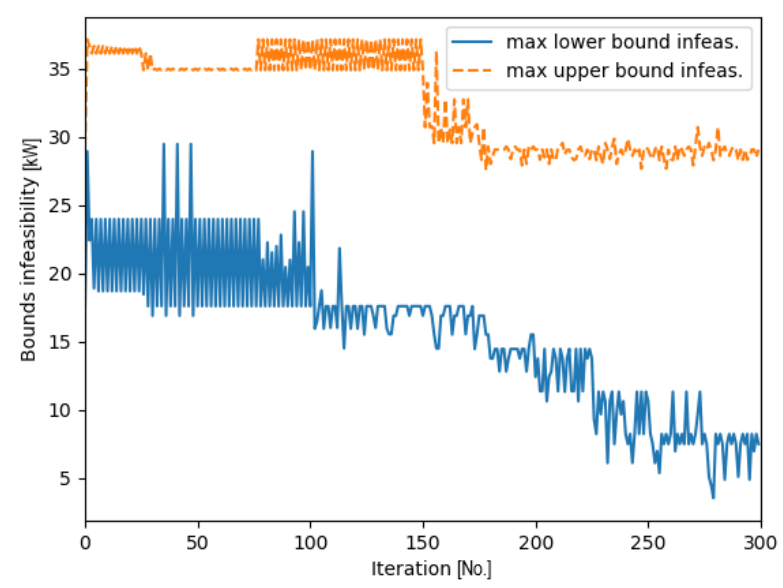

Fig. 6. Bound infeasibility.

households, as well as the net exchange by the community at

[2] Y. Parag and B. K. Sovacool, "Electricity market design for the prosumer era," Nature Energy, vol. 1, March 2016.

[3] Y. Wang, S. Wang, and L. Wu, "Distributed optimization approaches for emerging power systems operation: A review," Electric Power Systems Research, vol. 144, pp. 127-135, March 2017.

[4] D. K. Molzahn, F. Dörfler, H. Sandberg, S. H. Low, S. Chakrabarti, R. Baldick, and J. Lavaei, "A Survey of Distributed Optimization and Control Algorithms for Electric Power Systems," IEEE Transactions on Smart Grid, vol. 8, pp. 2941-2962, Nov. 2017.

[5] R. Vujanic, P. Mohajerin Esfahani, P. J. Goulart, S. Mariéthoz, and M. Morari, "A decomposition method for large scale MILPs, with performance guarantees and a power system application," Automatica, vol. 67, pp. 144-156, May 2016.

[6] A. Falsone, K. Margellos, and M. Prandini, "A decentralized approach to multi-agent MILPs: finite-time feasibility and performance guarantees," Automatica, vol. 103, pp. 141-150, May 2019. the transformer level, are portrayed in Fig. ??. In principle, the HEMS agents try to export electricity to the rest of the grid when the prices are high while maximizing individual and joint self-consumption.

\section{CONCLUSION}

In this paper, a method to solve a Mixed Integer Linear Program in a distributed way was applied to the problem of minimizing the electricity procurement cost of a community of Home Energy Management System agents. The objective behind this approach is to verify the applicability of methods that support decomposition of mixed integer optimization problems and provide guarantees for the feasibility of the primal solutions. The method was applied to a community of 15 residential households, the data of which were taken from a public data set. The simulation results show the expected behavior and the applicability of this method. Extending the scope of the problem and fine-tuning of parameters to improve the performance of the algorithm are considered to be part of future work.

\section{REFERENCES}

[1] N. G. Paterakis, O. Erdinç, and J. P. S. Catalão, "An overview of demand response: Key-elements and international experience," Renewable and Sustainable Energy Reviews, vol. 69, pp. 871 - 891, March 2017.

[7] N. G. Paterakis, O. Erdinç, I. N. Pappi, A. G. Bakirtzis, and J. P. S Catalão, "Coordinated operation of a neighborhood of smart households comprising electric vehicles, energy storage and distributed generation," IEEE Transactions on Smart Grid, vol. 7, pp. 2736-2747, Nov. 2016.

[8] Gurobi Optimization LLC, "Gurobi optimizer reference manual," 2018, [Accessed 2019-02-01]. [Online]. Available: http://www.gurobi.com

[9] "Pecan street dataport 2018," [Accessed 2019-02-01]. [Online]. Available: https://www.pecanstreet.org/dataport/

[10] ENTSO-E, "ENTSO-E Transparency Platform," [Accessed 2019-02-01]. [Online]. Available: https://transparency.entsoe.eu/ 